\title{
Review Article \\ Exosomes in the Repair of Bone Defects: Next-Generation Therapeutic Tools for the Treatment of Nonunion
}

\author{
Jian Lu, ${ }^{1,2}$ Qi-Yang Wang, ${ }^{1}$ and Jia-Gen Sheng ${ }^{1}{ }^{1}$ \\ ${ }^{1}$ Department of Orthopaedic Surgery, Shanghai Jiao Tong University Affiliated Sixth People's Hospital, \\ 600 Yishan Road, Shanghai 200233, China \\ ${ }^{2}$ The Third Affiliated Hospital of Soochow University, Changzhou, Jiangsu 213003, China
}

Correspondence should be addressed to Jia-Gen Sheng; shengjiagen@126.com

Received 13 March 2019; Accepted 22 July 2019; Published 4 August 2019

Academic Editor: Timo Gaber

Copyright (C) 2019 Jian Lu et al. This is an open access article distributed under the Creative Commons Attribution License, which permits unrestricted use, distribution, and reproduction in any medium, provided the original work is properly cited.

\begin{abstract}
Nonunion with bone defects, a common complication after long bone fracture, is a major challenge for orthopaedic surgeons worldwide because of the high incidence rate and difficulties in achieving successful treatment. Bone defects are the main complications of nonunion. The conventional biological treatments for nonunion with bone defects involve the use of autologous bone grafts or bone graft substitutes and cell-based therapy. Traditional nonunion treatments have always been associated with safety issues and various other complications. Bone grafts have limited autologous cancellous bone and there is a risk of infection. Additionally, problems with bone graft substitutes, including rejection and stimulation of bone formation, have been noted, and the health of the stem cell niche is a major consideration in cell-based therapy. In recent years, researchers have found that exosomes can be used to deliver functional RNA and mediate cell-to-cell communication, suggesting that exosomes may repair bone defects by regulating cells and cytokines involved in bone metabolism. In this review, we highlight the possible relationships between risk factors for nonunion and exosomes. Additionally, we discuss the roles of exosomes in bone metabolism and bone regeneration.
\end{abstract}

\section{Introduction}

Traumatic and life-threatening fractures of the long bones have increased dramatically as the demand for motor transport continues to increase in developing countries [1]. Nonunion is the most common complication after long bone fracture, and the rate of nonunion is estimated to be between $5 \%$ and $10 \%[2,3]$. In addition, the higher incidence rates of obesity and musculoskeletal diseases and reduced rates of bone regeneration [4] have increased the occurrence of nonunion [5]. Nonunion is not limited to developing countries but is experienced worldwide. According to the Food and Drug Administration, nonunion is considered if the fracture is not healed after a minimum of 9 months and there are no obvious progressive signs of healing for 3 consecutive months [6]. Patients with bone nonunion often require two or more surgeries, resulting in severe psychological and economic pressure $[7,8]$ and seriously affecting quality of life $[5,9]$. Therefore, an in-depth understanding of the fracture healing process and related mechanisms and the provision of appropriate interventions to accelerate bone regeneration are essential to avoid adverse consequences. Thus, given the burden of nonunion on patients and society, new treatments for nonunion intervention are urgently needed.

Extracellular vesicles are a class of heterogeneous membrane vesicles including three major subpopulations (exosomes, microvesicles, and apoptotic bodies), which has a great diversity of biophysical properties and functions. The International Society for Extracellular Vesicles updated their guidelines in 2018 (Table 1) [10]. Exosomes contain lipids, nucleic acids, proteins, and signalling molecules (Figure 1) [11]. Exosomes were first discovered and described as exfoliated membrane vesicles in 1981 [12]. Firstly, endosomes are produced by plasma membrane internalization of donor cells, and then the proteins and RNAs (including lncRNAs, circRNAs, mRNAs, and miRNAs) are selectively crated into the multivesicular bodies, via endosomal sorting complex required for transport- (ESCRT-) dependent or ESCRTindependent mechanisms. Subsequently, the multivesicular bodies are either fused to the lysosome for degradation 


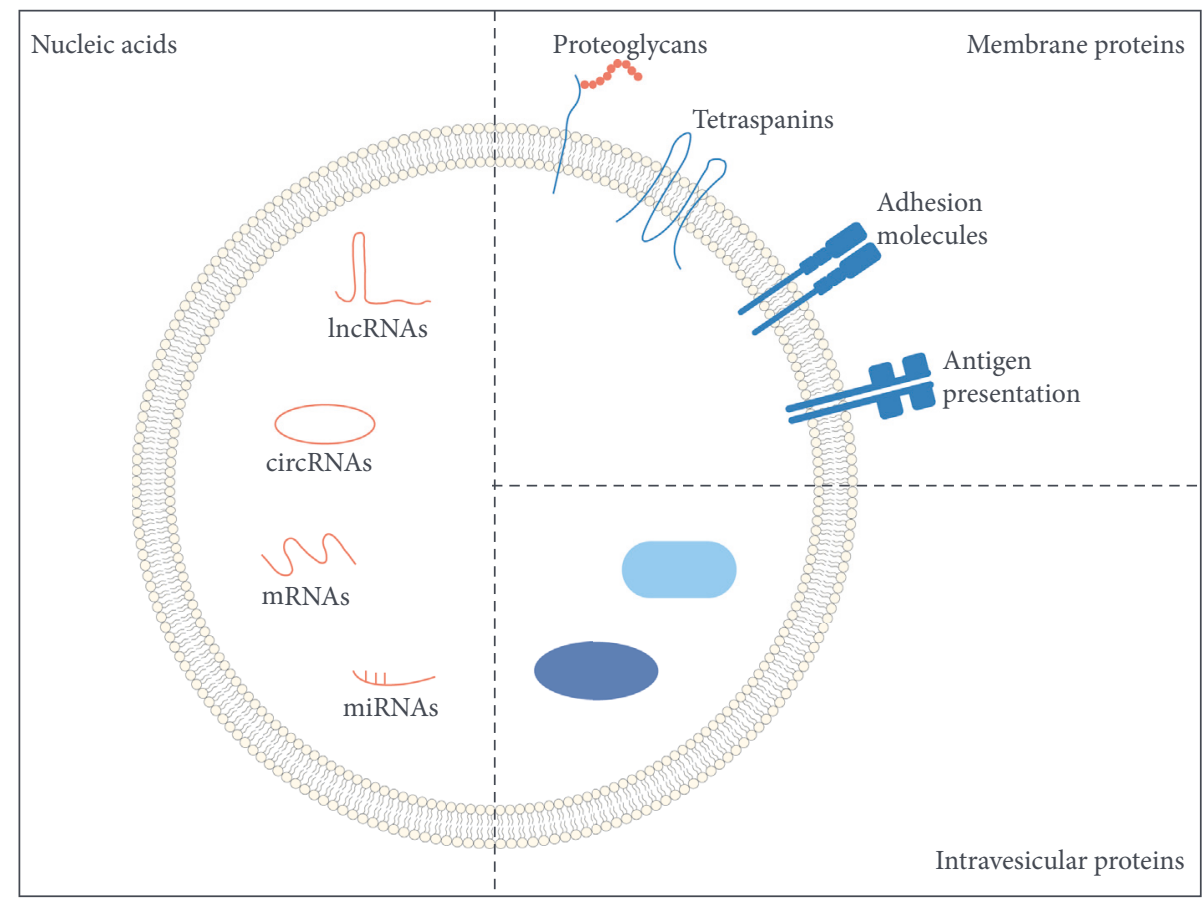

FIgURE 1: The constitute of exosomes.

TABLE 1: Types of extracellular vesicles.

\begin{tabular}{lcc}
\hline Vesicles & Size $(\mathrm{nm})$ & Origin \\
\hline Exosomes & $50-100$ & Endosomes \\
Microvesicles & $100-1,000$ & Plasma membrane \\
Apoptotic bodies & $1,000-5,000$ & Plasma membrane \\
\hline
\end{tabular}

or released into the extracellular space by fusion with the plasma membrane to produce exosomes. Microvesicles are produced directly on the plasma membrane \{Tao, 2018 \#264\}. Today, exosomes are defined as cellular organelles that are released by various tissues and cells and can be internalized by receptor cells through endocytosis [13]. Exosomes are widely distributed and can be separated from almost all types of biological fluids, particularly semen [14], breast milk [15], saliva [16], synovial fluid [17], and urine [18]. Recent studies have demonstrated that exosomes possess the ability to stimulate the regeneration and repair of tissue and organs [19], including the heart [20], skin [21], and liver [22]. In the past two decades, exosomes have been shown to have various applications as naturally derived nanoparticles. Endocytosis of exosomes can facilitate the absorption of proteins, mRNAs, and microRNAs, thereby affecting target cells [23]. Moreover, these functional RNAs enable intercellular signal communication through exosomes [24].

In this review, we discuss the applications of exosome treatment in nonunion with bone defects, highlighting the physiological mechanisms of fracture, risk factors that may cause nonunion, classifications of nonunion, and treatment intervention using exosomes.

\section{Fracture Healing}

Bone can heal without scarring and return to its original state, unlike other tissues [25], through the concerted activities of thousands of genes, cytokines, growth factors, chemokines, and other molecules [26]. The newly healed bone is similar in structure and mechanical properties to the original bone [27-29]. Fracture healing involves an initial anabolic stage in which tissue volume increases in relation to newly generated and differentiated stem cells, which form bone and vascular tissue (Figure 2) [30]. First, the injured bone forms a hematoma, which is a fibrin clot caused by periosteal blood vessel haemorrhage beneath the periosteum and the medullary canal [31] as a result of coagulation [32]. Although the mechanical properties are poor, the fibrin clot provides the first step for fracture connection [33]. Simultaneously, macrophages, degranulating platelets, and other inflammatory cells [34] reach the fracture site to clean up the wound [35]. Gradually, endothelial cells and fibroblasts infiltrate, forming new capillaries and collagen matrix, which results in the formation of granulation tissue $[32,36]$ to fill the fracture gap [37]. Initial granulation tissue is then gradually replaced by fibrous tissue, to form a soft callus [38]. Close to the hypoxic fracture line, as chondrocytes become hypertrophic and begin to undergo apoptosis, the soft callus exhibits endochondral ossification [26]. In the periphery of the new cartilage tissue toward the fracture location, periosteum swelling and bone formation occur through intramembranous ossification [39]. Additionally, following exposure to vascular endothelial growth factor secreted from endothelial cells, the surrounding matrix is digested by chondrocytes and then infiltrated by blood vessels and osteoblasts [40]. The next phase involves the formation of 


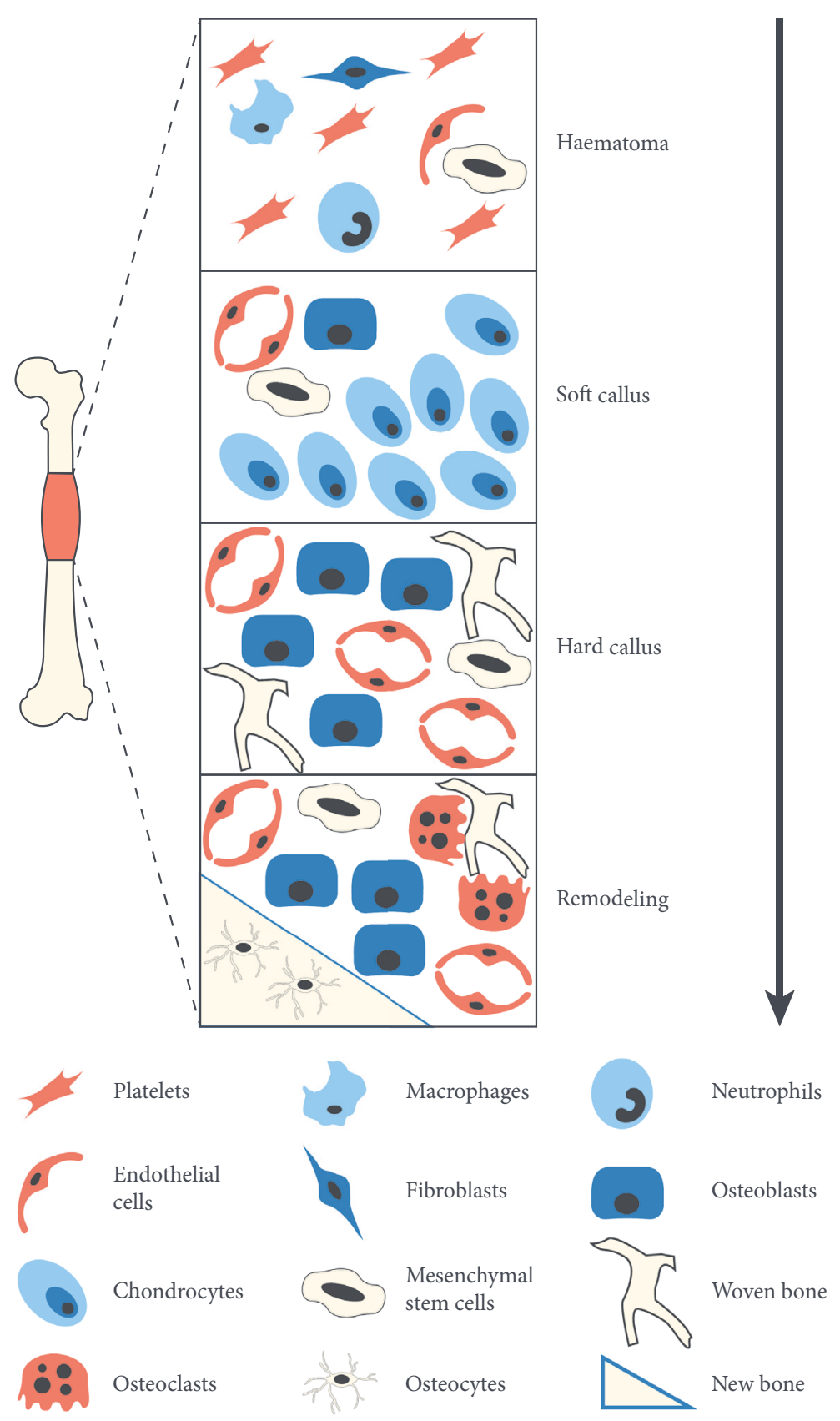

FIGURE 2: Cells involved in the process of bone healing.

the primary bone [34], which is characterized by replacement of mineralized bone and high levels of osteoblast activity [41], concurrent with cartilage tissue development.

2.1. Indirect (Secondary) Fracture Healing. Indirect healing with callus formation is an orderly process of bone recombination [42]. In general, using fixation with steel plates and screws, the fracture ends are better restored and compressively fixed. Micromotion and weight-bearing enhance indirect fracture healing. However, delayed union and nonunion can also appear when there is too much motion [43].
2.2. Direct Fracture Healing. Direct fracture healing can occur by lamellar bone remodelling when the fracture end is very stable with no gap formation. However, when natural healing of the fracture does not occur, this type of healing usually requires open reduction and internal fixation [42].

\section{Contribution of Risk factors to Fracture Nonunion}

The relationships between various risk factors affecting fracture healing and nonunion have been confirmed in 
recent studies [44]. Risk factors identified as contributing to the development of fracture nonunion include patientdependent factors, such as age [45] (age-related changes can affect many biological processes during fracture healing), sex [46] (high oestrogen levels in postmenopausal women play important roles in promoting bone formation), nutritional state $[47,48]$ (during the bone regeneration process, there is an increase in metabolic requirements), diabetes [49] (diabetes is a metabolic disorder that interferes with bone formation and damages fracture healing), osteoporosis [50] (osteoporosis impairs bone regeneration and the ability to restore biomechanical properties), alcohol abuse [51] (alcohol reduces bone repair, repaired tissue stiffness, and ash density), smoking [52] (nicotine inhibits osteoblast proliferation and is a vasoconstrictor, leading to tissue ischemia and hypoxia), and nonsteroidal anti-inflammatories (NSAIDs) [53] (longterm, high-dose treatment with NSAIDs reduces osteoblast numbers and inhibits the formation of prostaglandin). Patient-independent factors include fracture gap [54] (the fracture process is poor when the fracture gap is greater than $2 \mathrm{~cm}$ ), fracture site [55] (compared with bone fracture of the diaphysis, the incidence of healing defects in the metaphyseal fracture is lower and the healing time is shorter), type of fracture $[55,56]$ (compared with stable and simple fractures, the more ruptured and unstable the fracture ends, the higher the risk of debris ischemia and necrosis), and infection [57, 58] (infection reduces the strength of the callus and creates conditions for sequestrum and osteolysis). All strategies that help shorten healing time and restore work and activity faster not only improve patient outcomes but also help reduce the financial burden of fracture and nonunion.

\section{Classification of Nonunion}

The most common classification of nonunions is the Weber and Cech classification [59]. Nonunions include hypertrophic nonunion and atrophic nonunion. Hypertrophic nonunion, also called mechanical nonunion, involves a large number of nonbridged calluses containing cartilage and is characterized by excessive bone formation and poor mechanical fixation. Atrophic nonunion, also called biological nonunion, is characterized by minimal callus or cartilage owing to lack of blood supply or cells. In atrophic nonunion, the fracture end may be hardened or osteoporotic [60].

\section{Treatment Intervention}

Long bone nonunion is often accompanied with bone defects. For management of nonunion, the main strategies include removal of necrotic bone and tissue, filling most of the bone defect, promoting the recruitment of osteoblasts, increasing the concentrations of osteoinductive substances, and providing a stable mechanical environment [61]. The distribution of blood vessels at the site of nonunion has also been shown to be an important factor in fracture healing [62]. In this section, we summarize various types of reconstruction treatments to achieve bone healing and maintain limb length.
5.1. Surgical Intervention. In order to regenerate hard and soft tissue defects, mechanical stability can be promoted through surgical intervention [61].

Nail dynamization: After treatment of long bone fractures with intramedullary nails, dynamization of intramedullary nails may help increase axial compression and micromotion to stimulate healing $[63,64]$. This method may cause axial shortening of the femur via dynamization [65].

Exchange nailing with augmentation plating: Exchange nailing provides biological effects by increasing subperiosteal blood circulation and stimulating osteogenesis [66], growth factor activation $[67,68]$, and inflammatory responses [69]. As the length of the medullary stenosis and diameter of the intramedullary nail increase, the effective contact area between the intramedullary nail and the medullary cavity is significantly increased, thereby enhancing mechanical stability [70, 71].

Augmentation plating: Rotational instability is also a risk factor in diaphyseal long bone nonunion, which can be solved by augmentation plating $[72,73]$.

External fixation: External fixation to treat nonunion provides tension and support at the long bone nonunion sites for bone binding $[74,75]$. The procedure can improve early weight bearing while increasing the stability of bone healing [76]. The disadvantages of this procedure are that it takes a long time to heal and that the wound is at risk of infection [77].

However, surgical intervention can only overcome factors affecting instability and is not sufficient to cure nonunion. Treatment of nonunion involves not just providing a stable mechanical environment for nonunion but also increasing osteogenic activity to address biological nonunion.

5.2. Autograft and Other Bone Graft Substitutes. Autologous bone grafts are the "gold standard" for the treatment of nonunion because of complete histocompatibility and strong osteoconduction, osteoinduction, and osteogenic activities [78]. However, autograft bone grafts may result in increased blood loss, pain, and possible infection at the donor site [79]. Although allogeneic bone has no osteogenic potential, it can be used as a scaffold to provide osteoconductive material [80]. Demineralized bone matrix is composed of collagen, noncollagenous proteins, bone morphogenic proteins, and growth factors [81], conferring the bone with osteoinductive and some oeteoconductive properties [82]. Ceramics, such as calcium phosphate [83], tricalcium phosphate [84], hydroxyapatite [85], and calcium sulphate [86], have been widely used as osteoinductive carriers and transplant substitutes. Among them, calcium phosphate is chemically similar to human bone minerals and also have bioconductive [87]. Le Nihouannen D [88] proved that microporous biphasic calcium phosphate containing hydroxyapatite and betatricalcium phosphate implants into sheep muscle can promote bone formation. Le Nihouannen D et al. [89] also used calcium phosphate ceramics as scaffold combined with fibrin glue based composites to verify osteoinduction (new bone formation) and osteoconduction (bone healing capacity). However, allogeneic bone and bone graft substitutes 
may be associated with infection [90] and graft-versus-host disease [91]. Moreover, bone graft substitutes have no cellular components, and their effects are not as good as autologous bone.

5.3. Cell Therapy. Cell-based therapies, which apply a stem cell self-sufficient biological environment and heterogeneity to restore and improve tissue function, have been extensively investigated. Friendstein et al. found that, after hematopoietic necrosis, osteoblast-like bone marrow cells formed new bone in vitro, and mesenchymal stem cells (MSCs) were first isolated in this context [92]. Bruder et al. demonstrated for the first time that MSCs isolated from human bone marrow could regenerate normal bone in critical tibial defects of immunocompromised rats [93]. Additionally, MSCs were found to be ideal cells for bone tissue regeneration, not only because of their therapeutic potential and ability to self-renew but also because of their availability from many different tissues [94-96].

Bone marrow-derived stem cells (BMSCs): BMSCs are the most abundant cells in the bone marrow. BMSCs play roles in regulating hematopoietic stem cells and progenitor cells through different signalling pathways, as demonstrated in various studies [97]. When treating nonunion, Connolly et al. reported that 18 of 20 patients with ununited tibial fractures were successfully cured by autologous marrow injection into the nonunion site [98]. Additionally, Quarto et al. [99] and Marcacci et al. [100] have achieved healing results with bone graft substitutes loaded with BMSCs. Similar treatments such as BMSCs and biphasic calcium phosphate biomaterials have been transplanted in nonunion to achieve effective fracture healing and bone growth in clinical trials [101]. This work was supported by European Union's Seventh Framework Programme (FP7/FP7-HEALTH-2009).

Induced pluripotent stem cells (iPSCs): Human iPSCs are similar to embryonic stem cells in multilineage differentiation potential and proliferation ability [102]. Teramura et al. [103] demonstrated that mouse iPSCs could be induced into MSClike cells and then differentiated into osteoblasts. Although the study of iPSCs is still relatively new, iPSCs may have promising applications in the healing of bone defects.

Other stem cells also have shown excellent osteogenesis capacity. For example, endothelial progenitor cells can form ectopic vascular bone for the treatment of critical size bone defects [104]. In animal studies hydroxyapatite-tricalcium phosphate containing allogeneic MCSs were effective in enhancing the repair of critical-sized defect in the canine femur $[105,106]$. Although the treatment outcomes of these novel methods are promising, the molecular mechanisms of MSC repair in vivo are still unclear. Increasing evidence suggests that the therapeutic effects of MSCs are related to exosome-mediated paracrine induction $[107,108]$.

5.4. Cell-Free Therapy. Many studies have supported the roles of exosomes in intercellular communication through paracrine signalling in various tissue repair processes and diseases (Figure 3) [109]. These natural mechanisms can be applied as intercellular signalling pathways to stimulate bone regeneration [109]. Therefore, cell-free therapies that increase the formation of osteoblasts and the interactions between cells may have potential applications in the treatment of nonunion.

As an important component of exosomes, microRNAs have attracted much attention in the study of exosome function owing to their important regulatory roles. Li et al. reported that osteoclast-derived exosomal miR-214-3p inhibits osteogenic activity and reduces bone formation; additionally, inhibition of $m i R-214-3 p$ in osteoclasts may have applications in the treatment of nonunion [110]. Qin and colleagues found that muscle-secreting myostatin inhibits osteoblastic differentiation by blocking osteocyte-derived exosomal $m i R-218$, suggesting the presence of a potential communication mechanism between muscle and bone [111]. Weilner et al. reported that $m i R$-31 from vascular endothelial cell-derived exosomes may be a biomarker and potential therapeutic target for osteoporosis [112].

Proteins in exosomes in cell-to-cell communication also play important roles. Ge et al. reported that highly expressed proteins in MC3T3 cell-derived exosomes are rich in osteogenic-related pathways [113]. Moreover, Huynh et al. reported that receptor activator of nuclear factor- $\kappa \mathrm{B}$ ligand (RANK), which is highly enriched in exosomes derived from osteoclasts, is a paracrine regulator of osteoclastogenesis [114].

Many recent studies have evaluated the application of stem cell-derived exosomes for bone repair. Qin et al. demonstrated that BMSC-derived exosomes regulate osteoblast expression by miR-196a in vitro and improve bone regeneration ability in a Sprague-Dawley rat model of calvarial defects [115]. Additionally, angiogenesis has been shown to be an essential factor in bone regeneration. Ashoo et al. demonstrated that BMSC-derived exosomes are capable of increasing endothelial cell viability in vitro and stimulating angiogenesis in vivo [116]. Lu et al. also reported that adipose stem cell-derived exosomes promote the proliferation and differentiation of human primary osteoblastic cells [117]. Exosomes released from adipose stem cells (ASCs) have also been shown to promote ASCs-induced angiogenesis [118].

Proteins and RNAs contained in osteoblasts-derived exosomes played an important role in intercellular communication within bone tissue. Ge et al. demonstrated that osteoblast-derived exosomes activate eukaryotic factor 2 to promote osteoblastic differentiation in vitro [113]. Weilner et al. demonstrated that galectin-3 levels in osteoblasts-derived exosomes were positively correlated with osteogenesis potential [119]. A proteomic study of exosomes derived from MC3T3 cells (mouse osteoblasts) revealed some osteogenesis-related pathways, including integrin signalling, mammalian target of rapamycin (mTOR) signalling, and eukaryotic initiation factor 2 (EIF2) signalling [113]. Moreover, Cui et al. reported that mineralizing osteoblastderived exosomes promoted bone marrow stromal cell differentiation into osteoblasts by activating Wnt signalling [120].

Exosomes have been widely reported in the field of regeneration. Qi et al. found that exosomes secreted by MSCs 


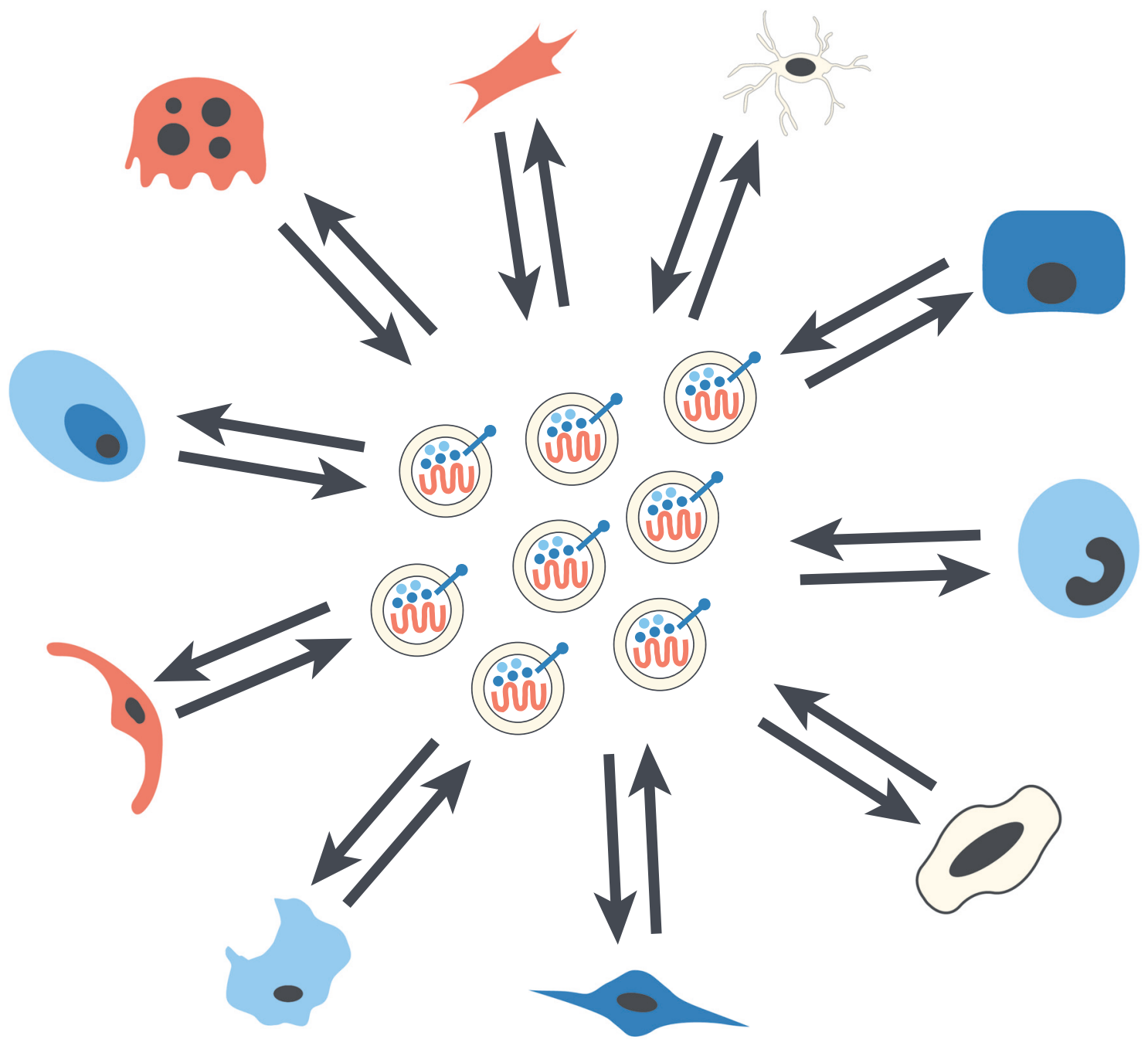

FIgURE 3: Exosomes are likely to be the way cells communicate with each other in the process of bone healing.

derived from human induced pluripotent stem cells (hiPSCMSC-Exos) could significantly promote osteogenesis and angiogenesis in rats with osteoporosis [121]. Liu et al. found that, in a model of steroid-induced osteonecrosis in rats, hiPSC-MSC-Exos could prevent femoral head necrosis by activating PI3K/Akt signaling pathways in endothelial cells to promote angiogenesis [122]. In another study, compared with exosomes secreted by synovial membrane MSCs (SMMSCExos), exosomes secreted by induced pluripotent stem cellderived MSCs (iMSC-Exos) had superior therapeutic effect on osteoarthritis (OA) due to the ability to promote chondrocyte migration and proliferation [123]. Du et al. reported that hiPSC-MSC-Exos could alleviate hepatic ischemiareperfusion $(\mathrm{I} / \mathrm{R})$ injury and promote cell proliferation in a rat model of hepatic I/R injury [124].

\section{Discussion and Conclusion}

Nonunion has major implications for patients and families and can also affect society. Surgical intervention can only solve mechanical nonunion, and interventions for biological bone nonhealing often involve autologous bone or bone graft substitutes, stem cell therapy, and other methods. Nonviable vesicles, such as exosomes, are associated with a lower risk of complications than cell-based treatment. Importantly, exosomes can be stored at $-20^{\circ} \mathrm{C}$ for 6 months without loss of efficacy [125]. Thus, it is particularly important to grasp the relationship between exosome and nonunion healing mechanisms and to solve the problem of nonunion.

Osteoblasts, osteoclasts, proangiogenic factors, and blood platelets play important roles in fracture healing. As described above, osteoblasts release exosomes in a positive feedback loop to promote bone growth [113]. Inder and colleagues reported that prostate cancer cell-derived exosomes can attenuate osteoclast formation and stimulate osteoblast proliferation [126]. In addition to osteoclastderived exosomes, which can affect osteoclast differentiation, Raimondi et al. reported that multiple myeloma-derived exosomes increase $\mathrm{C}-\mathrm{X}-\mathrm{C}$ motif chemokine receptor 4 expression and activation, thus promoting osteoclast maturation [127]. Additionally, Solberg et al. showed that lysosomal membrane protein 1-positive exosomes contain 
RANK ligand, osteoprotegerin, and tartrate-resistant acid phosphatase isolated from rat osteoblasts and osteocytes [128]. Osteoclast formation can be stimulated by RANKLrich osteoblast-derived exosomes, as shown by Deng et al. [129]. In promoting angiogenesis, exosomes can stimulate endothelial cell migration and angiogenesis through exosomal miR-129 and $m i R-136$ [116]. Torreggiani et al. reported that BMSCs treated with platelet-derived exosomes containing proteins and noncoding RNAs showed a significant increase in osteogenesis [130]. Understanding the processes and secreted components of cells involved in fracture healing may guide the development of new treatments for nonunion.

There are some factors that can explain the nonunion of fractures, and treatment of nonunion with these factors can be achieved through the use of exosomes. $\mathrm{Xu}$ et al. found that $m i R-31 a-5 p$ in rat bone marrow stromal cellderived exosomes prevents age-related bone loss and reduces osteoclast activity in rats. Thus, they proposed that miR$31 a-5 p$ may be an age-related potential therapeutic target [131]. Notably, women have a higher probability of developing arthritis than men, and women who are postmenopausal are at increased risk [132]; Kolhe et al. noted that differences in miRNA expression were greater in women with osteoarthritis than in men with osteoarthritis [133], suggesting that some differences in miRNA contents may be related to sex. Additionally, Saha et al. analysed plasmaderived exosomes from alcoholic individuals and reported that alcohol increases exosome production in monocytes; they also found that exosomes containing $m i R-27 a$ released from monocytes promoted naïve monocyte differentiation into M2 macrophages [134]. Goerzl et al. demonstrated that aspirin significantly reduces the levels of plasma plateletderived exosomes without changing the total number of exosomes [135].

Exosomes have great potential for applications in the treatment of nonunion with bone defects and can be used to adjust the immune microenvironment and promote vascularization, proliferation, differentiation, and mineralization of osteoblasts. Exosomes are eliminated from the blood stream in short time and aggregate in the liver [136, 137]. Thus, future studies are needed to further assess the application and efficiency of exosome-based targeted drug delivery.

\section{Conflicts of Interest}

The authors declare that they have no competing interests.

\section{Authors' Contributions}

Jian $\mathrm{Lu}$ is the first author and planned and wrote the manuscript. Qi-Yang Wang helped with the writing. Jia-Gen Sheng provided advice and suggestions. All authors reviewed the manuscript.

\section{Acknowledgments}

The authors acknowledge the NHFPC Special Fund for Health Scientific Research in the Public Welfare (grant no.
201402016) and Joint Project Funding for Major Diseases in Shanghai (grant no. 2014ZYJB0301) for supporting our work.

\section{References}

[1] B. Jiang, S. Liang, Z.-R. Peng et al., "Transport and public health in China: the road to a healthy future," The Lancet, vol. 390, no. 10104, pp. 1781-1791, 2017.

[2] C. Tzioupis and P. V. Giannoudis, "Prevalence of long-bone non-unions," Injury, vol. 38, no. 2, pp. S3-S9, 2007.

[3] M. van Griensven, "Preclinical testing of drug delivery systems to bone," Advanced Drug Delivery Reviews, vol. 94, pp. 151-164, 2015.

[4] M. J. Chehade and A. Bachorski, "Development of the australian core competencies in musculoskeletal basic and clinical science project - phase 1," Medical Journal of Australia, vol. 189, no. 3, pp. 162-165, 2008.

[5] P. V. Giannoudis, E. Jones, and T. A. Einhorn, "Fracture healing and bone repair," Injury, vol. 42, no. 6, pp. 549-550, 2011.

[6] G. Calori, E. L. Mazza, S. Mazzola et al., "Non-unions," Clinical Cases in Mineral And Bone Metabolism: The Official Journal of The Italian Society of Osteoporosis, Mineral Metabolism, And Skeletal Diseases, vol. 14, no. 2, pp. 186-188, 2017.

[7] K. J. Bozic, A. G. Rosenberg, R. S. Huckman, and J. H. Herndon, "Economic evaluation in orthopaedics," Journal of Bone and Joint Surgery, vol. 85A, pp. 129-142, 2003.

[8] D. J. Hak, D. Fitzpatrick, J. A. Bishop et al., "Delayed union and nonunions: epidemiology, clinical issues, and financial aspects," Injury, vol. 45, supplement 2, pp. S3-S7, 2014.

[9] W. H. Geerts, J. A. Heit, G. P. Clagett et al., "Prevention of venous thromboembolism," Chest, vol. 119, no. 1, pp. 132S-175S, 2001.

[10] C. Thery, K. W. Witwer, E. Aikawa et al., "Minimal information for studies of extracellular vesicles 2018 (MISEV2018): a position statement of the international society for extracellular vesicles and update of the MISEV2014 guidelines," Journal of Extracellular Vesicles, vol. 7, Article ID 1535750, 2018.

[11] K. Trajkovic, C. Hsu, S. Chiantia et al., "Ceramide triggers budding of exosome vesicles into multivesicular endosomes," Science, vol. 319, no. 5867, pp. 1244-1247, 2008.

[12] E. G. Trams, C. J. Lauter, J. Norman Salem, and U. Heine, "Exfoliation of membrane ecto-enzymes in the form of microvesicles," Biochimica et Biophysica Acta, vol. 645, no. 1, pp. 6370, 1981.

[13] A. E. Morelli, A. T. Larregina, W. J. Shufesky et al., "Endocytosis, intracellular sorting, and processing of exosomes by dendritic cells," Blood, vol. 104, no. 10, pp. 3257-3266, 2004.

[14] K. Skriner, K. Adolph, P. R. Jungblut, and G. R. Burmester, "Association of citrullinated proteins with synovial exosomes," Arthritis \& Rheumatology, vol. 54, no. 12, pp. 3809-3814, 2006.

[15] G. Ronquist and I. Brody, "The prostasome: its secretion and function in man," Biochimica et Biophysica Acta, vol. 822, no. 2, pp. 203-218, 1985.

[16] M. P. Caby, D. Lankar, C. Vincendeau-Scherrer, G. Raposo, and C. Bonnerot, "Exosomal-like vesicles are present in human blood plasma," International Immunology, vol. 17, no. 7, pp. 879887, 2005.

[17] A. I. Masyuk, B. Q. Huang, C. J. Ward et al., "Biliary exosomes influence cholangiocyte regulatory mechanisms and proliferation through interaction with primary cilia," American Journal of Physiology-Gastrointestinal and Liver Physiology, vol. 299, no. 4, pp. G990-G999, 2010. 
[18] Y. Ogawa, Y. Miura, A. Harazono et al., "Proteomic analysis of two types of exosomes in human whole saliva," Biological \& Pharmaceutical Bulletin, vol. 34, no. 1, pp. 13-23, 2011.

[19] S. Zhang, W. C. Chu, R. C. Lai, S. K. Lim, J. H. P. Hui, and W. S. Toh, "Exosomes derived from human embryonic mesenchymal stem cells promote osteochondral regeneration," Osteoarthritis and Cartilage, vol. 24, no. 12, pp. 2135-2140, 2016.

[20] R. C. Lai, F. Arslan, M. M. Lee et al., "Exosome secreted by MSC reduces myocardial ischemia/reperfusion injury," Stem Cell Research, vol. 4, no. 3, pp. 214-222, 2010.

[21] B. Zhang, Y. Yin, R. C. Lai, S. S. Tan, A. B. H. Choo, and S. K. Lim, "Mesenchymal stem cells secrete immunologically active exosomes," Stem Cells and Development, vol. 23, no. 11, pp. 12331244, 2014.

[22] C. Y. Tan, R. C. Lai, W. Wong, Y. Y. Dan, S.-K. Lim, and H. K. Ho, "Mesenchymal stem cell-derived exosomes promote hepatic regeneration in drug-induced liver injury models," Stem Cell Research \& Therapy, vol. 5, no. 3, article 76, 2014.

[23] N. Heldring, I. Mäger, M. J. A. Wood, K. Le Blanc, and S. E. L. Andaloussi, "Therapeutic potential of multipotent mesenchymal stromal cells and their extracellular vesicles," Human Gene Therapy, vol. 26, no. 8, pp. 506-517, 2015.

[24] N. Kosaka, H. Iguchi, Y. Yoshioka, F. Takeshita, Y. Matsuki, and T. Ochiya, "Secretory mechanisms and intercellular transfer of microRNAs in living cells," The Journal of Biological Chemistry, vol. 285, no. 23, pp. 17442-17452, 2010.

[25] R. Marsell and T. A. Einhorn, "The biology of fracture healing," Injury, vol. 42, no. 6, pp. 551-555, 2011.

[26] D. E. Komatsu and S. J. Warden, "The control of fracture healing and its therapeutic targeting: improving upon nature," Journal of Cellular Biochemistry, vol. 109, no. 2, pp. 302-311, 2010.

[27] T. A. Einhorn, "The cell and molecular biology of fracture healing," Clinical Orthopaedics and Related Research, Supplement 355, pp. S7-S21, 1998.

[28] T. Nyary and B. E. Scammell, "Principles of bone and joint injuries and their healing," Surgery (United Kingdom), vol. 36, no. 1, pp. 7-14, 2018.

[29] B. McKibbin, "The biology of fracture healing in long bones," The Journal of Bone \& Joint Surgery (British Volume), vol. 60, no. 2, pp. 150-162, 1978.

[30] T. A. Einhorn and L. C. Gerstenfeld, "Fracture healing: mechanisms and interventions," Nature Reviews Rheumatology, vol. 11, pp. 45-54, 2014.

[31] P. M. Mountziaris and A. G. Mikos, "Modulation of the inflammatory response for enhanced bone tissue regeneration," Tissue Engineering Part B: Reviews, vol. 14, no. 2, pp. 179-186, 2008.

[32] H. T. Shiu, P. C. Leung, and C. H. Ko, "The roles of cellular and molecular components of a hematoma at early stage of bone healing," Journal of Tissue Engineering and Regenerative Medicine, vol. 12, no. 4, pp. e1911-e1925, 2018.

[33] K. Schmidt-Bleek, H. Schell, N. Schulz et al., "Inflammatory phase of bone healing initiates the regenerative healing cascade," Cell and Tissue Research, vol. 347, no. 3, pp. 567-573, 2012.

[34] L. C. Gerstenfeld, D. M. Cullinane, G. L. Barnes, D. T. Graves, and T. A. Einhorn, "Fracture healing as a post-natal developmental process: molecular, spatial, and temporal aspects of its regulation," Journal of Cellular Biochemistry, vol. 88, no. 5, pp. 873-884, 2003.

[35] K. D. Hankenson, G. Zimmerman, and R. Marcucio, "Biological perspectives of delayed fracture healing," Injury, vol. 45, no. 2, pp. S8-S15, 2014.
[36] L. C. Gerstenfeld, T.-J. Cho, T. Kon et al., "Impaired fracture healing in the absence of TNF- $\alpha$ signaling: the role of TNF- $\alpha$ in endochondral cartilage resorption," Journal of Bone and Mineral Research, vol. 18, no. 9, pp. 1584-1592, 2003.

[37] J. Goldhahn, J.-M. Féron, J. Kanis et al., "Implications for fracture healing of current and new osteoporosis treatments: an ESCEO consensus paper," Calcified Tissue International, vol. 90, no. 5, pp. 343-353, 2012.

[38] L. Geris, A. Gerisch, J. V. Sloten, R. Weiner, and H. V. Oosterwyck, "Angiogenesis in bone fracture healing: A bioregulatory model," Journal of Theoretical Biology, vol. 251, no. 1, pp. 137-158, 2008.

[39] A. Phillips, "Overview of the fracture healing cascade," Injury, vol. 36, no. 3, pp. S5-S7, 2005.

[40] Z. Hao, J. Lu, S. Wang, H. Wu, Y. Zhang, and S. Xu, "Stem cellderived exosomes: A promising strategy for fracture healing," Cell Proliferation, vol. 50, no. 5, p. e12359, 2017.

[41] D. D. Thomson, "Introduction-mechanisms of fracture healing and pharmacologic control," Journal of Musculoskeletal \& Neuronal Interactions, vol. 3, pp. 295-296, 2003.

[42] M. Greenbaum and I. Kanat, "Current concepts in bone healing. Review of the literature," Journal of the American Podiatric Medical Association, vol. 83, no. 3, pp. 123-129, 1993.

[43] E. Green, J. D. Lubahn, and J. Evans, "Risk factors, treatment, and outcomes associated with nonunion of the midshaft humerus fracture," Journal of Surgical Orthopaedic Advances , vol. 14, no. 2, pp. 64-72, 2005.

[44] P. Giannoudis, C. Tzioupis, T. Almalki, and R. Buckley, "Fracture healing in osteoporotic fractures: Is it really different?" Injury, vol. 38, no. 1, pp. S90-S99, 2007.

[45] D. Clark, M. Nakamura, T. Miclau, and R. Marcucio, "Effects of aging on fracture healing," Current Osteoporosis Reports, vol. 15, no. 6, pp. 601-608, 2017.

[46] J. L. Jr. Esterhai, C. T. Brighton, R. B. Heppenstall, and A. Thrower, "Nonunion of the humerus. Clinical, roentgenographic, scintigraphic, and response characteristics to treatment with constant direct current stimulation of osteogenesis," Clinical Orthopaedics and Related Research, pp. 228-234, 1986.

[47] T. Cederholm and M. Hedström, "Nutritional treatment of bone fracture," Current Opinion in Clinical Nutrition \& Metabolic Care, vol. 8, no. 4, pp. 377-381, 2005.

[48] T. A. Einhorn, F. Bonnarens, and A. H. Burstein, "The contributions of dietary protein and mineral to the healing of experimental fractures. A biomechanical study.," The Journal of Bone \& Joint Surgery, vol. 68, no. 9, pp. 1389-1395, 1986.

[49] H. Jiao, E. Xiao, and D. T. Graves, "Diabetes and its effect on bone and fracture healing," Current Osteoporosis Reports, vol. 13, no. 5, pp. 327-335, 2015.

[50] V. Hegde, J. E. Jo, P. Andreopoulou, and J. M. Lane, "Effect of osteoporosis medications on fracture healing," Osteoporosis International, vol. 27, no. 3, pp. 861-871, 2016.

[51] C. Trevisiol, R. Turner, J. Pfaff et al., "Impaired osteoinduction in a rat model for chronic alcohol abuse," Bone, vol. 41, no. 2, pp. 175-180, 2007.

[52] B. Ziran, S. Cheung, W. Smith, and K. Westerheide, "Comparative efficacy of 2 different demineralized bone matrix allografts in treating long-bone nonunions in heavy tobacco smokers," The American Journal of Orthopedics, vol. 34, no. 7, pp. 329-332, 2005.

[53] P. Geusens, P. J. Emans, J. J. A. de Jong, and J. van den Bergh, "NSAIDs and fracture healing," Current Opinion in Rheumatology, vol. 25, no. 4, pp. 524-531, 2013. 
[54] L. Claes, P. Augat, G. Suger, and H.-J. Wilke, "Influence of size and stability of the osteotomy gap on the success of fracture healing," Journal of Orthopaedic Research, vol. 15, no. 4, pp. 577584, 1997.

[55] G. Calori, W. Albisetti, A. Agus, S. Iori, and L. Tagliabue, "Risk factors contributing to fracture non-unions," Injury, vol. 38, pp. S11-S18, 2007.

[56] M. E. Muller, "Treatment of nonunion by compression," Clinical Orthopaedics and Related Research, p. 43, 1965.

[57] F. Bilgili, H. I. Balci, K. Karaytug et al., "Can normal fracture healing be achieved when the implant is retained on the basis of infection? an experimental animal model," Clinical Orthopaedics and Related Research, vol. 473, no. 10, pp. 31903196, 2015.

[58] A. Hulth, "Current concepts of fracture healing," Clinical Orthopaedics and Related Research, pp. 265-284, 1989.

[59] B. G. Weber and O. Cech, "Pseudoarthrosis: Pathology biomechanics therapy results berne," 1976.

[60] J. G. Andrew, J. Hoyland, S. M. Andrew, A. J. Freemont, and D. Marsh, "Demonstration of TGF- $\beta 1$ mRNA by in situ hybridization in normal human fracture healing," Calcified Tissue International, vol. 52, no. 2, pp. 74-78, 1993.

[61] P. V. Giannoudis, T. A. Einhorn, and D. Marsh, "Fracture healing: the diamond concept," Injury, vol. 38, no. 4, pp. S3-S6, 2007.

[62] H. C. Fayaz, P. V. Giannoudis, M. S. Vrahas et al., "The role of stem cells in fracture healing and nonunion," International Orthopaedics, vol. 35, no. 11, pp. 1587-1597, 2011.

[63] U. Kandemir, "Distal femur: dynamization of plating," Injury, vol. 49, pp. S44-S48, 2018.

[64] V. Glatt, C. H. Evans, and K. Tetsworth, "A concert between biology and biomechanics: The influence of the mechanical environment on bone healing," Frontiers in Physiology, vol. 7, article no. 678, 2017.

[65] C. Wu, "The effect of dynamization on slowing the healing of femur shaft fractures after interlocking nailing," The Journal of Trauma: Injury, Infection, and Critical Care, vol. 43, no. 2, pp. 263-267, 1997.

[66] M. R. Brinker and D. P. O’Connor, "Exchange nailing of ununited fractures," The Journal of Bone \& Joint Surgery, vol. 89, no. 1, pp. 177-188, 2007.

[67] M. Bhandari and E. H. Schemitsch, "Bone formation following intramedullary femoral reaming is decreased by indomethacin and antibodies to insulin-like growth factors," Journal of Orthopaedic Trauma, vol. 16, no. 10, pp. 717-722, 2002.

[68] F. Högel, C. Gerber, V. Bühren, and P. Augat, "Reamed intramedullary nailing of diaphyseal tibial fractures: comparison of compression and non-compression nailing," European Journal of Trauma and Emergency Surgery, vol. 39, no. 1, pp. 7377, 2013.

[69] R. M. Smith, P. V. Giannoudis, M. C. Bellamy, S. L. Perry, R. A. Dickson, and P. J. Guillou, "Interleukin-10 release and monocyte human leukocyte antigen-dr expression during femoral nailing," Clinical Orthopaedics and Related Research, vol. 373, pp. 233-240, 2000.

[70] S. E. Utvåg, O. Grundnes, and O. Reikerås, "Graded exchange reaming and nailing of non-unions," Archives of Orthopaedic and Trauma Surgery, vol. 118, no. 1-2, pp. 1-6, 1998.

[71] C. Hierholzer, J. Friederichs, C. Glowalla, A. Woltmann, V. Bühren, and C. von Rüden, "Reamed intramedullary exchange nailing in the operative treatment of aseptic tibial shaft nonunion," International Orthopaedics, vol. 41, no. 8, pp. 16471653, 2017.

[72] Y. S. Choi and K. S. Kim, "Plate augmentation leaving the nail in situ and bone grafting for non-union of femoral shaft fractures," International Orthopaedics, vol. 29, no. 5, pp. 287-290, 2005.

[73] C. Lin, C. Chiang, P. Wu et al., "Effectiveness of plate augmentation for femoral shaft nonunion after nailing," Journal of the Chinese Medical Association, vol. 75, no. 8, pp. 396-401, 2012.

[74] G. A. Ilizarov, "The tension-stress effect on the genesis and growth of tissues," Clinical Orthopaedics and Related Research, vol. 238, pp. 249-281, 1989.

[75] K. Kaspar, G. Matziolis, P. Strube et al., "A new animal model for bone atrophic nonunion: Fixation by external fixator," Journal of Orthopaedic Research, vol. 26, no. 12, pp. 1649-1655, 2008.

[76] H. Zhang, F. Xue, and H. Jun Xiao, "Ilizarov method in combination with autologous mesenchymal stem cells from iliac crest shows improved outcome in tibial non-union," Saudi Journal of Biological Sciences, vol. 25, no. 4, pp. 819-825, 2018.

[77] A. M. Abdel-Aal, "Ilizarov bone transport for massive tibial bone defects," Orthopedics, vol. 29, no. 1, pp. 70-74, 2006.

[78] S. N. Khan, F. P. Cammisa, H. S. Sandhu, A. D. Diwan, F. P. Girardi, and J. M. Lane, “The biology of bone grafting," Journal of the American Academy of OrthopaedicSurgeons, vol. 13, no. 1, pp. 77-86, 2005.

[79] T. J. Dekker, P. White, and S. B. Adams, "Efficacy of a cellular bone allograft for foot and ankle arthrodesis and revision nonunion procedures," Foot \& Ankle International, vol. 38, no. 3, pp. 277-282, 2017.

[80] K. M. Emara, R. A. Diab, and A. K. Emara, "Recent biological trends in management of fracture non-union," World Journal of Orthopedics, vol. 6, no. 8, pp. 623-628, 2015.

[81] T. T. Roberts and A. J. Rosenbaum, "Bone grafts, bone substitutes and orthobiologics the bridge between basic science and clinical advancements in fracture healing," Organogenesis, vol. 8, no. 4, pp. 114-124, 2012.

[82] W. S. Pietrzak, S. V. Perns, J. Keyes, J. Woodell-May, and N. M. McDonald, "Demineralized bone matrix graft: a scientific and clinical case study assessment," The Journal of Foot \& Ankle Surgery, vol. 44, no. 5, pp. 345-353, 2005.

[83] O. Gauthier, J. Bouler, E. Aguado, P. Pilet, and G. Daculsi, "Macroporous biphasic calcium phosphate ceramics: influence of macropore diameter and macroporosity percentage on bone ingrowth," Biomaterials, vol. 19, no. 1-3, pp. 133-139, 1998.

[84] K. Ohura, M. Bohner, P. Hardouin, J. Lemaître, G. Pasquier, and B. Flautre, "Resorption of, and bone formation from, new $\beta$-tricalcium phosphate-monocalcium phosphate cements: An in vivo study," Journal of Biomedical Materials Research Part B: Applied Biomaterials, vol. 30, no. 2, pp. 193-200, 1996.

[85] R. W. Bucholz, A. Carlton, and R. E. Holmes, "Hydroxyapatite and tricalcium phosphate bone-graft substitutes," Orthopedic Clinics of North America, vol. 18, pp. 323-334, 1987.

[86] C. M. Kelly, R. M. Wilkins, S. Gitelis, C. Hartjen, J. T. Watson, and P. T. Kim, "The use of a surgical grade calcium sulfate as a bone graft substitute," Clinical Orthopaedics and Related Research, vol. 382, pp. 42-50, 2001.

[87] G. Daculsi, "Smart scaffolds: the future of bioceramic," Journal of Materials Science: Materials in Medicine, vol. 26, no. 4, 2015.

[88] D. Lenihouannen, G. Daculsi, A. Saffarzadeh et al., "Ectopic bone formation by microporous calcium phosphate ceramic particles in sheep muscles," Bone, vol. 36, no. 6, pp. 1086-1093, 2005. 
[89] D. L. Nihouannen, A. Saffarzadeh, E. Aguado et al., "Osteogenic properties of calcium phosphate ceramics and fibrin glue based composites," Journal of Materials Science: Materials in Medicine, vol. 18, no. 2, pp. 225-235, 2007.

[90] A. Giordano, U. Galderisi, and I. R. Marino, "From the laboratory bench to the patient's bedside: an update on clinical trials with mesenchymal stem cells," Journal of Cellular Physiology, vol. 211, no. 1, pp. 27-35, 2007.

[91] H. Dinopoulos, R. Dimitriou, and P. V. Giannoudis, "Bone graft substitutes: what are the options?" The Surgeon : Journal of The Royal Colleges of Surgeons of Edinburgh And Ireland, vol. 10, pp. 230-239, 2012.

[92] A. J. Friedenstein, K. V. Petrakova, A. I. Kurolesova, and G. P. Frolova, "Heterotopic of bone marrow. Analysis of precursor cells for osteogenic and hematopoietic tissues," Transplantation, vol. 6, no. 2, pp. 230-247, 1968.

[93] S. P. Bruder, A. A. Kurth, M. Shea, W. C. Hayes, N. Jaiswal, and S. Kadiyala, "Bone regeneration by implantation of purified, culture-expanded human mesenchymal stem cells," Journal of Orthopaedic Research, vol. 16, no. 2, pp. 155-162, 1998.

[94] A. I. Caplan, "All MSCs are pericytes?" Cell Stem Cell, vol. 3, no. 3, pp. 229-230, 2008.

[95] A. Martins, M. L. Alves da Silva, S. Faria, A. P. Marques, R. L. Reis, and N. M. Neves, "The influence of patterned nanofiber meshes on human mesenchymal stem cell osteogenesis," Macromolecular Bioscience, vol. 11, no. 7, pp. 978-987, 2011.

[96] J. R. Perez, D. Kouroupis, D. J. Li, T. M. Best, L. Kaplan, and D. Correa, "Tissue engineering and cell-based therapies for fractures and bone defects," Frontiers in Bioengineering and Biotechnology, vol. 6, article no. 105, 2018.

[97] A. García-García, C. L. F. de Castillejo, and S. Méndez-Ferrer, "BMSCs and hematopoiesis," Immunology Letters, vol. 168, pp. 129-135, 2015.

[98] J. F. Connolly, R. Guse, J. Tiedeman, and R. Dehne, "Autologous marrow injection as a substitute for operative grafting of tibial nonunions," Clinical Orthopaedics and Related Research, pp. 259-270, 1991.

[99] R. Quarto, M. Mastrogiacomo, R. Cancedda et al., "Repair of large bone defects with the use of autologous bone marrow stromal cells," The New England Journal of Medicine, vol. 344, no. 5, pp. 385-386, 2001.

[100] M. Marcacci, E. Kon, V. Moukhachev et al., "Stem cells associated with macroporous bioceramics for long bone repair: 6- to 7-year outcome of a pilot clinical study," Tissue Engineering Part A, vol. 13, no. 5, pp. 947-955, 2007.

[101] E. Gómez-Barrena, P. Rosset, F. Gebhard et al., "Feasibility and safety of treating non-unions in tibia, femur and humerus with autologous, expanded, bone marrow-derived mesenchymal stromal cells associated with biphasic calcium phosphate biomaterials in a multicentric, non-comparative trial," Biomaterials, vol. 196, pp. 100-108, 2019.

[102] K. Takahashi, K. Tanabe, M. Ohnuki et al., "Induction of pluripotent stem cells from adult human fibroblasts by defined factors," Cell, vol. 131, no. 5, pp. 861-872, 2007.

[103] T. Teramura, Y. Onodera, T. Mihara, Y. Hosoi, C. Hamanishi, and K. Fukuda, "Induction of mesenchymal progenitor cells with chondrogenic property from mouse-induced pluripotent stem cells," Cellular Reprogramming, vol. 12, no. 3, pp. 249-261, 2010.

[104] N. C. Keramaris, S. Kaptanis, H. L. Moss, M. Loppini, S. Pneumaticos, and N. Maffulli, "Endothelial progenitor cells
(EPCs) and mesenchymal stem cells (MSCs) in bone healing," Current Stem Cell Research \& Therapy, vol. 7, no. 4, pp. 293-301, 2012.

[105] T. L. Arinzeh, "Mesenchymal stem cells for bone repair: preclinical studies and potential orthopedic applications," Foot and Ankle Clinics, vol. 10, no. 4, pp. 651-665, 2005.

[106] T. L. Arinzeh, S. J. Peter, M. P. Archambault et al., "Allogeneic mesenchymal stem cells regenerate bone in a critical-sized canine segmental defect," The Journal of bone and joint surgery American volume, vol. 85, pp. 1927-1935, 2003.

[107] L. Kordelas, V. Rebmann, A. K. Ludwig et al., "MSC-derived exosomes: a novel tool to treat therapy-refractory graft-versushost disease," Leukemia, vol. 28, pp. 970-973, 2014.

[108] S. C. Tao, S. C. Guo, and C. Q. Zhang, "Modularized extracellular vesicles: the dawn of prospective personalized and precision medicine," Advanced Science, vol. 5, no. 2, Article ID 1700449, 2018.

[109] Y. Nakamura, S. Miyaki, H. Ishitobi et al., "Mesenchymal-stemcell-derived exosomes accelerate skeletal muscle regeneration," FEBS Letters, vol. 589, no. 11, pp. 1257-1265, 2015.

[110] D. Li, J. Liu, B. Guo et al., "Osteoclast-derived exosomal miR214-3p inhibits osteoblastic bone formation," Nature Communications, vol. 7, Article ID 10872, 2016.

[111] Y. Qin, Y. Peng, W. Zhao et al., "Myostatin inhibits osteoblastic differentiation by suppressing osteocyte-derived exosomal microRNA-218: A novel mechanism in muscle-bone communication," The Journal of Biological Chemistry, vol. 292, no. 26, pp. 11021-11033, 2017.

[112] S. Weilner, E. Schraml, M. Wieser et al., "Secreted microvesicular miR-31 inhibits osteogenic differentiation of mesenchymal stem cells," Aging Cell, vol. 15, no. 4, pp. 744-754, 2016.

[113] M. Ge, R. Ke, T. Cai, J. Yang, and X. Mu, "Identification and proteomic analysis of osteoblast-derived exosomes," Biochemical and Biophysical Research Communications, vol. 467, no. 1, pp. 27-32, 2015.

[114] N. Huynh, L. VonMoss, D. Smith et al., "Characterization of regulatory extracellular vesicles from osteoclasts," Journal of Dental Research, vol. 95, no. 6, pp. 673-679, 2016.

[115] Y. Qin, L. Wang, Z. Gao, G. Chen, and C. Zhang, "Bone marrow stromal/stem cell-derived extracellular vesicles regulate osteoblast activity and differentiation in vitro and promote bone regeneration in vivo," Scientific Reports, vol. 6, no. 1, Article ID 21961, 2016.

[116] S. Sahoo, E. Klychko, T. Thorne et al., "Exosomes from human $\mathrm{CD} 34^{+}$stem cells mediate their proangiogenic paracrine activity," Circulation Research, vol. 109, no. 7, pp. 724-728, 2011.

[117] Z. Lu, Y. Chen, C. Dunstan, S. Roohani-Esfahani, and H. Zreiqat, "Priming adipose stem cells with tumor necrosis factoralpha preconditioning potentiates their exosome efficacy for bone regeneration," Tissue Engineering Part A, vol. 23, no. 21-22, pp. 1212-1220, 2017.

[118] T. Lopatina, S. Bruno, C. Tetta, N. Kalinina, M. Porta, and G. Camussi, "Platelet-derived growth factor regulates the secretion of extracellular vesicles by adipose mesenchymal stem cells and enhances their angiogenic potential," Cell Communication and Signaling, vol. 12, no. 1, article 26, 2014.

[119] S. Weilner, V. Keider, M. Winter et al., "Vesicular Galectin-3 levels decrease with donor age and contribute to the reduced osteo-inductive potential of human plasma derived extracellular vesicles," AGING, vol. 8, no. 1, pp. 16-30, 2016. 
[120] Y. Cui, J. Luan, H. Li, X. Zhou, J. Han, and Z. Chang, "Exosomes derived from mineralizing osteoblasts promote ST2 cell osteogenic differentiation by alteration of microRNA expression," FEBS Letters, vol. 590, no. 1, pp. 185-192, 2016.

[121] X. Qi, J. Zhang, H. Yuan et al., "Exosomes secreted by humaninduced pluripotent stem cell-derived mesenchymal stem cells repair critical-sized bone defects through enhanced angiogenesis and osteogenesis in osteoporotic rats," International Journal of Biological Sciences, vol. 12, no. 7, pp. 836-849, 2016.

[122] X. Liu, Q. Li, X. Niu et al., "Exosomes secreted from humaninduced pluripotent stem cell-derived mesenchymal stem cells prevent osteonecrosis of the femoral head by promoting angiogenesis," International Journal of Biological Sciences, vol. 13, no. 2, pp. 232-244, 2017.

[123] Y. Zhu, Y. Wang, B. Zhao et al., "Comparison of exosomes secreted by induced pluripotent stem cell-derived mesenchymal stem cells and synovial membrane-derived mesenchymal stem cells for the treatment of osteoarthritis," Stem Cell Research \& Therapy, vol. 8, no. 1, article no. 64, 2017.

[124] Y. Du, D. Li, C. Han et al., "Exosomes from human-induced pluripotent stem cell-derived mesenchymal stromal cells (hiPSC-MSCs) protect liver against hepatic ischemia/ reperfusion injury via activating sphingosine kinase and sphingosine-1phosphate signaling pathway," Cellular Physiology and Biochemistry, vol. 43, no. 2, pp. 611-625, 2017.

[125] B. Yu, X. Zhang, and X. Li, "Exosomes derived from mesenchymal stem cells," International Journal of Molecular Sciences, vol. 15, no. 3, pp. 4142-4157, 2014.

[126] K. L. Inder, J. E. Ruelcke, L. Petelin et al., "Cavin-1/PTRF alters prostate cancer cell-derived extracellular vesicle content and internalization to attenuate extracellular vesicle-mediated osteoclastogenesis and osteoblast proliferation," Journal of Extracellular Vesicles (JEV), vol. 3, no. 1, 2014.

[127] L. Raimondi, A. De Luca, N. Amodio et al., "Involvement of multiple myeloma cell-derived exosomes in osteoclast differentiation," Oncotarget , vol. 6, no. 15, pp. 13772-13789, 2015.

[128] L. B. Solberg, E. Stang, S. Brorson, G. Andersson, and F. P. Reinholt, "Tartrate-resistant acid phosphatase (TRAP) colocalizes with receptor activator of NF-KB ligand (RANKL) and osteoprotegerin (OPG) in lysosomal-associated membrane protein 1 (LAMP1)-positive vesicles in rat osteoblasts and osteocytes," Histochemistry and Cell Biology, vol. 143, no. 2, pp. 195-207, 2015.

[129] L. Deng, Y. Wang, Y. Peng et al., "Osteoblast-derived microvesicles: a novel mechanism for communication between osteoblasts and osteoclasts," Bone, vol. 79, pp. 37-42, 2015.

[130] E. Torreggiani, F. Perut, L. Roncuzzi, N. Zini, S. R. Baglìo, and N. Baldini, "Exosomes: Novel effectors of human platelet lysate activity," European Cells and Materials, vol. 28, pp. 137-151, 2014.

[131] R. Xu, X. Shen, Y. Si et al., "MicroRNA-31a-5p from aging BMSCs links bone formation and resorption in the aged bone marrow microenvironment," Aging Cell, vol. 17, no. 4, Article ID e12794, 2018.

[132] A. D. Woolf and B. Pfleger, "Burden of major musculoskeletal conditions," Bulletin of the World Health Organization, vol. 81, no. 9, pp. 646-656, 2003.

[133] R. Kolhe, M. Hunter, S. Liu et al., "Gender-specific differential expression of exosomal miRNA in synovial fluid of patients with osteoarthritis," Scientific Reports, vol. 7, no. 1, Article ID 2029, 2017.

[134] B. Saha, F. Momen-Heravi, K. Kodys, and G. Szabo, "MicroRNA cargo of extracellular vesicles from alcohol-exposed monocytes signals naive monocytes to differentiate into M2 macrophages," The Journal of Biological Chemistry, vol. 291, no. 1, pp. 149-159, 2016.

[135] E. J. Goetzl, L. Goetzl, J. S. Karliner, N. Tang, and L. Pulliam, "Human plasma platelet-derived exosomes: effects of aspirin," The FASEB Journal, vol. 30, no. 5, pp. 2058-2063, 2016.

[136] M. Morishita, Y. Takahashi, M. Nishikawa et al., "Quantitative analysis of tissue distribution of the B16BL6-derived exosomes using a streptavidin-lactadherin fusion protein and Iodine-125labeled biotin derivative after intravenous injection in mice," Journal of Pharmaceutical Sciences, vol. 104, no. 2, pp. 705-713, 2015.

[137] T. Imai, Y. Takahashi, M. Nishikawa et al., "Macrophagedependent clearance of systemically administered B16BL6derived exosomes from the blood circulation in mice," Journal of Extracellular Vesicles (JEV), vol. 4, article 26238, 2015. 


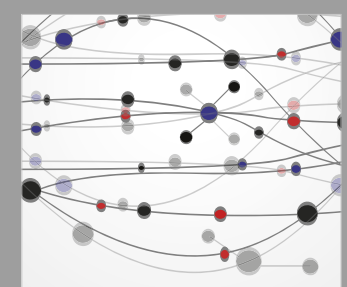

The Scientific World Journal
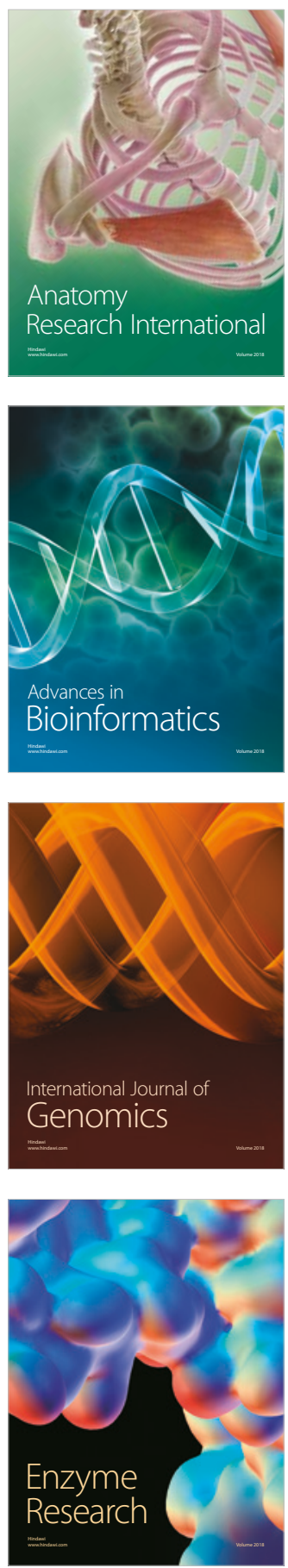
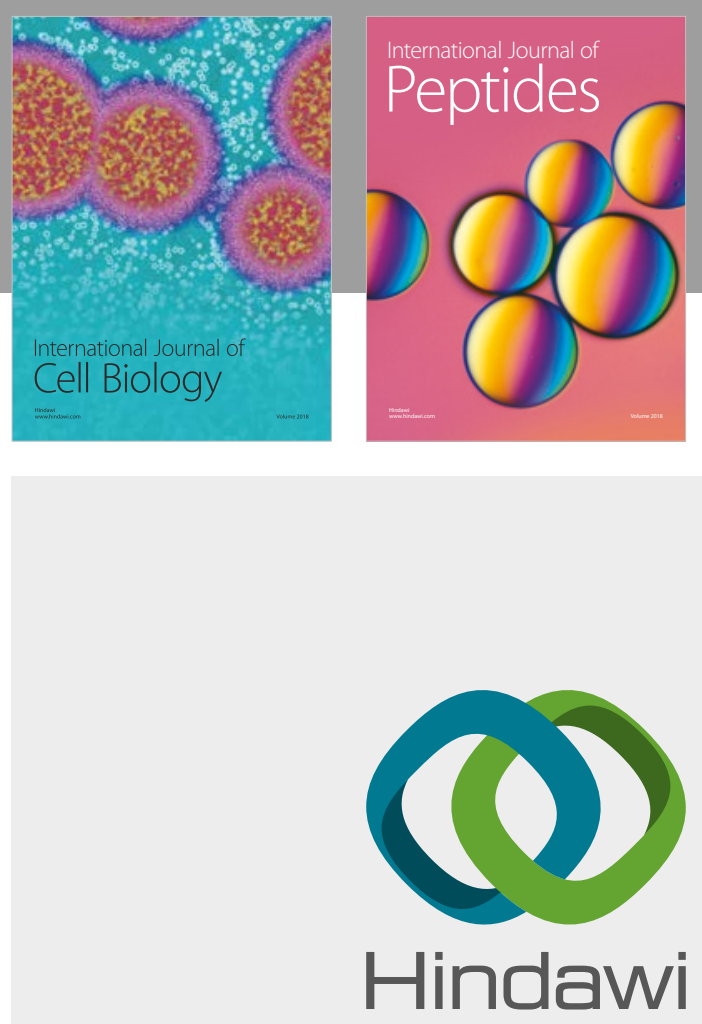

Submit your manuscripts at

www.hindawi.com
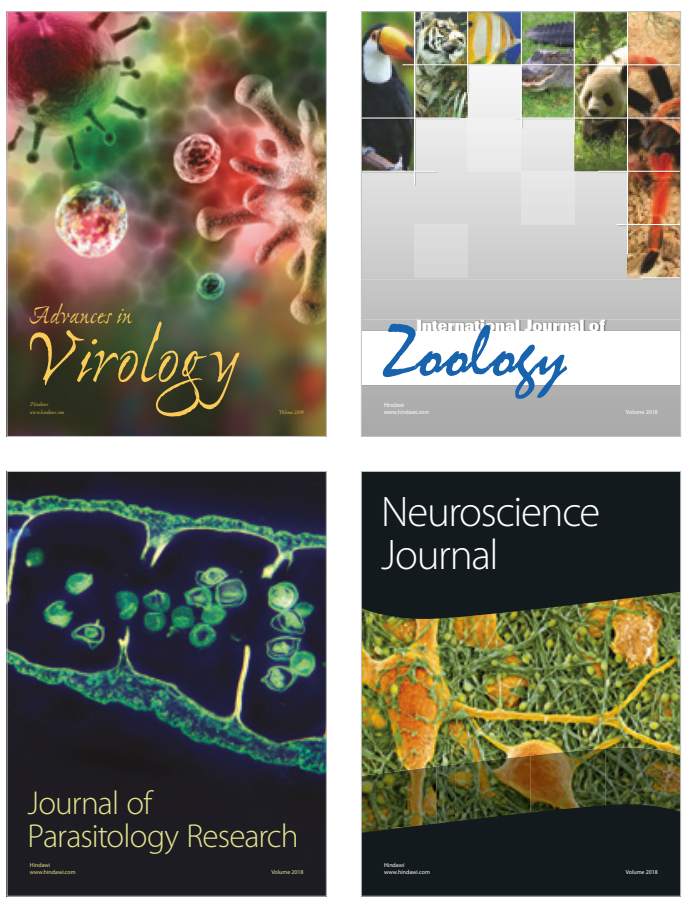
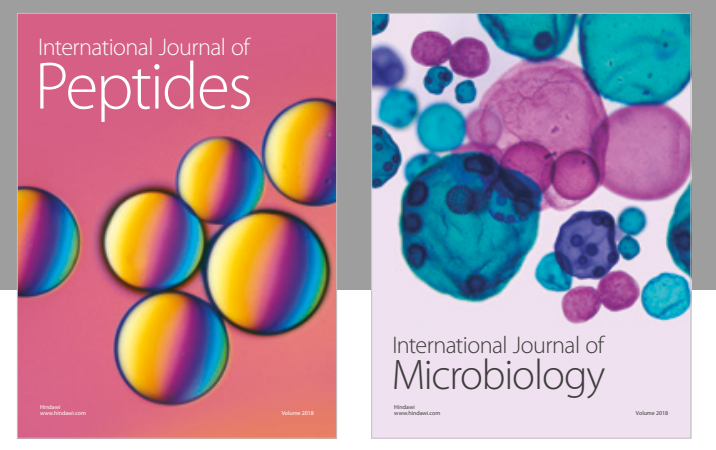

nternational Journal of Microbiology
Journal of
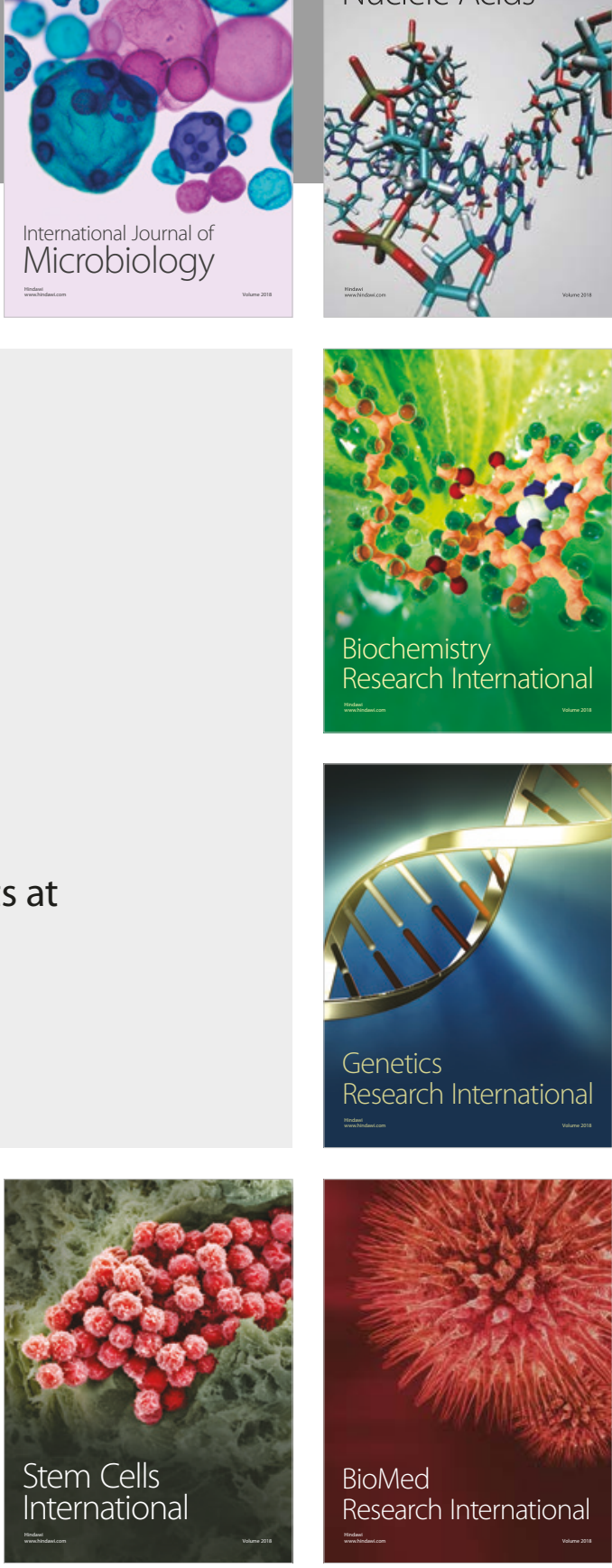
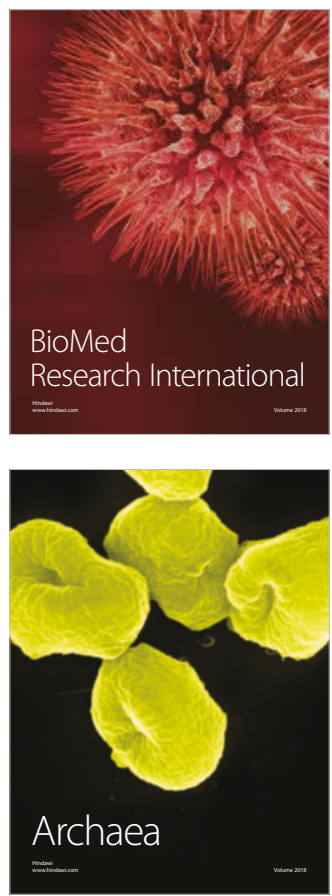